\title{
ELECTRON MICROSCOPIST
}

The National Center for Electron Microscopy (NCEM) currently has an opening for an Electron Microscopist/Materials Scientist to develop and lead a research program on the electron optical characterization and experimental control of materials microstructures.

The selected candidate will focus on the development and creative use of high resolution transmission electron microscopy as a quantitative technique and a major research tool including installation, testing and utilization of a new high resolution instrument. Other duties include providing project leadership in the development of new imaging methods and their applications to critical problems; presenting experimental results; developing proposals and preparing reports to funding agencies; initiating user collaborations both within the Center and Lawrence Berkeley Laboratory and with the external scientific community; and supervising technical staff.

We require an outstanding record of original research in materials sciences and electron microscopy; a strong background in transmission electron microscopy; knowledge of theoretical and practical principles of electron optical instrumentation and their application to significant problems in fundamental or applied materials research; demonstrated experience in experimental and theoretical high resolution imaging and analysis; proven experience in initiating and sustaining successful scientific collaborations; ability to be a team leader and team member; and good verbal/written communication skills. Ph.D. in physical sciences desired.

This is a 1-year term appointment with possibility of renewal and/or conversion to career. Submit your resume, publication record and names of three references to: Lawrence Berkeley Laboratory, Staffing Office, Box \#JMRS2266, One Cyclotron Road, Bldg. 938A, Berkeley, CA 94720. LBL is an EEO/AA employer committed to the development of a diverse workforce.

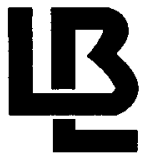

\section{LAWRENCE BERKELEY LABORATORY UNIVERSITY OF CALIFORNIA \\ U. S. Department of Energy}


Positions Available

\section{SILICON SUBSTRATE LABORATORY SUPERVISOR}

Dutles: Supervise and train laboratory technicians in analyzing and characterizing silicon samples using (1) total reflection $x$-ray fluorescence machine and maintaining same, (2) scanning electron microscope, (3) energy dispersive $x$-ray machine, (4) surface photovoltaic lifetime tester, (5) gas fusion analysis, (6) angle lapping technique for defect analysis, (7) photoluminescence, (8) Fourier transform infrared spectroscopy, (9) oxide breakdown voltage test, (10) capacitance vs. voltage measurement, (11) capacitance vs. time measurement. Analyze data, recommend procedures to solve quality and yield problems, prepare progress reports, develop and improve techniques to measure and evaluate silicon substrate materials, and participate in scientific societies and seminars to learn new relevant technology, increase personal skills, and enhance company image in these areas.

Requirements: PhD degree with major field of study in electrical engineering or materials science. Three years' work experience in semiconductor silicon substrate laboratory research and: (1) ability to conduct research and prepare written reports concerning electrical and chemical characteristics, yield and quality problems, and production techniques, of polished and epitaxial silicon substrate materials, as evidenced by the completion of at least two major research projects which have been peer reviewed and presented to one or more relevant scientific seminars and/or published in a scientific journal; (2) experience in connection with the analysis and characterization of polished and epitaxial silicon substrate materials using and maintaining total reflection $x$-ray fluorescence machine; and using (1) scanning electron microscope, (2) energy dispersive $x$-ray machine, (3) surface photovoltaic lifetime tester, (4) gas fusion analysis, (5) angle lapping technique for defect analysis, (6) photoluminescence, (7) Fourier transform infrared spectroscopy, (8) oxide breakdown voltage test, (9) capacitance vs. voltage measurement, (10) capacitance vs. time measurement; (3) Familiarity with the various gallium arsenide compounds and their uses, analysis and characterization in silicon substrate materials.

Salary: $\$ 50,419.20 /$ year. Full time position: 40 hours/week. Location: Salem, Oregon

DIRECT RESUMES AND REFERENCES TO: Job Order No. 5550678

Oregon State Employment Division, Department of Human Resources

875 Union Street, N.E., Room 201, Salem, OR 97311

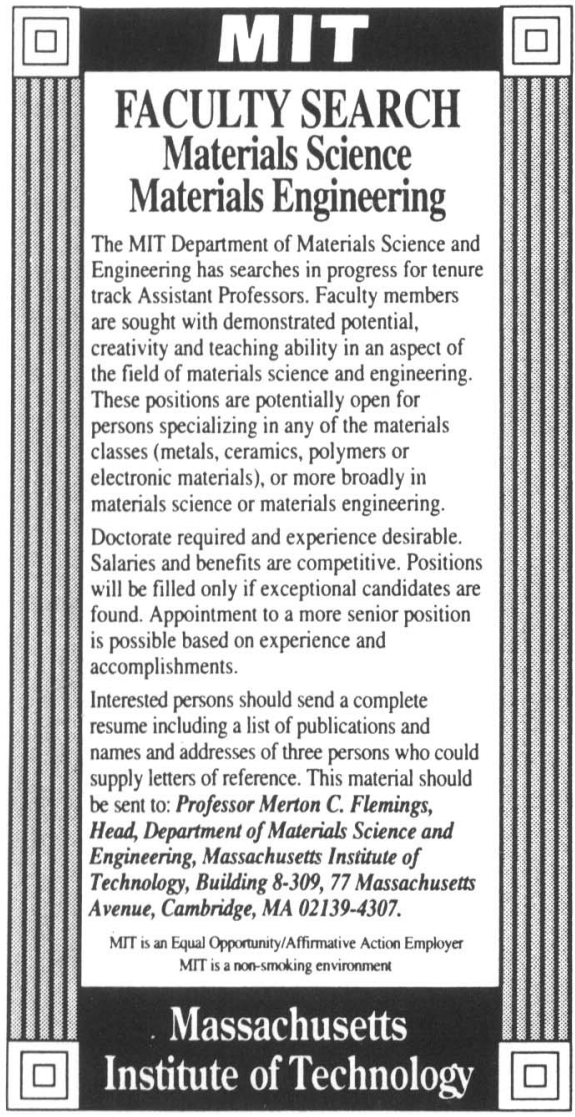

\section{PROCESS SUPPORT ENGINEER}

Retirement has created an attractive open position in our components development and manufacturing function at our Promeon Division in Brooklyn Center, $\mathrm{MN}$. This individual will provide the technical expertise in thin film and vacuum technology and provide support to our wire sputtering processes. Other responsibilities include developing and maintaining state-of-the-art technology in this field and other coating technologies to ensure technological leadership in product design, manufacturability and prob. lem solving.

A degree in engineering, material or physical science is required with a minimum of 6 years experience in deposition of thin films, plasma vacuum technology, metallurgy of thin films and material testing. Medical device, FDA/GMP experience is a plus.

Please send resume in confidence to: Vern Brewers, Medtronic, Inc., 6700 Shingle Creek Pkwy., Brooklyn Center, MN 55430. Equal Opportunity Employer $M / F$.

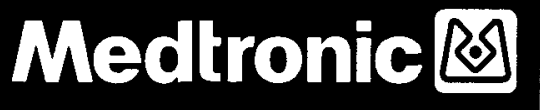

\section{ASSOCIATE DIRECTOR \\ Center for Nondestructive Evaluation \\ The Johns Hopkins University}

The Johns Hopkins University Center for Nondestructive Evaluation (CNDE) is seeking a qualified person to serve as associate director. The associate director is expected to be proficient in fund raising, organization of technical meetings, writing reports and newsletters, as well as to provide general assistance to the CNDE director. Applicants must have an earned doctoral degree in a scientific or engineering discipline, demonstrated excellence in research development, and professional credentials sufficient to be named a research professor in the Department of Materials Science and Engineering. Candidates should submit a resume which includes their professional achievements, names, addresses, and telephone numbers of at least three professional references to:

Prof. Robert E. Green Jr.

Director, Center for

Nondestructive Evaluation

Maryland Hall 102

The Johns Hopkins University

Baltimore, Maryland 21218

The Johns Hopkins University is an Equal Opportunity/Affirmative Action employer. Minorities and women are strongly encouraged to apply.

\section{Positions Wanted}

The following advertisements are from MRS members seeking employment in materials research and development.

PROSPECTIVE EMPLOYERS-

To correspond confidentially with the applicant,

REPLY TO THE APPROPRIATE BOX NUMBER, AS FOLLOWS:

Box c/o MRS Bulletin

Materials Research Society 9800 McKnight Road

Pittsburgh, PA 15237-6006

Electrochemist/Materials Scientist-Extensive industrial R\&D experience in batteries, plating, corrosion, erosion, photo-chemical and photoelectrochemical etching, thin-film hard coating, electro-galvanizing, and electrochemical metallurgy. Responsibilities include project management, proposal and report writing, and supervising. PhD in materials science and metallurgical engineering. U.S. citizen. Seeking career opportunity in production or research. Also considering joint effort in promoting technologies and marketing in Far East area. Employers-Please reply to BoX XIX, 601 . 


\section{Positions Wanted}

Versatile Bulldog/PhD/Multidisciplinary

Skills and 12-year record, developing/commer-

cializing composites, and engineering thermoplastics and thermosets for emerging marketse.g., ESD, EMl, fiber optics. Seek senior technical position and project management responsibilities in dynamic company. Experienced liaison to manufacturing, marketing, customers, US/foreign licensing and ventures. Willing to relocate travel (25\%). Employers-Please reply to Box XIX, 604.

Materials Scientist (PhD 1991) seeks challenging and continuing research and development position. Experience with solid-state chemical sensors, electroluminescent display devices and photovoltaics. Extensive experience with many thin-film deposition and characterization techniques. Broad educational background in materials science and physical and solid-state chemistry. Employers-Please reply to Box $\mathrm{XIX}, 602$.
PhD seeks research position. 15 years research experience in industry, defense, and educational environment. Expertise in radiation physics of semiconductors, properties of defects both in silicon and in semiconductor devices. Pulsed laser processing for integrated circuit manufacturing. High-energy electron/neutron/ gamma processing of semiconductors. Familiar with number of outstanding scientists in all former Soviet areas. Employers-Please reply to Box XIX, 605.

Physicist, PhD in materials science (electronic materials) soeks industrial/academic research position. Substantial experience with metal/|I-VI semiconductor interfaces, phase equilibria, reaction diffusion, thin film deposition of intermetallic phases, DTA, XRD, SEM/EDS, AES and analysis of electrical contact properties. Fluent German and English, basic Spanish. Employers-Please reply to Box XIX, 603 .
Research/Engineer position sought in industry/academia/national lab in development and characterization of materials. Extensive experience with AEA, TEM, SEM, XRD, photoemission, optical properties and electronic structure, ellipsometry, ultrahigh vacuum. Long experience working in university labs, computer modeling of inelastic scattering of electrons using Monte Carlo. PhD in materials science, $\mathrm{PhD}$ in physics. U.S. citizen. Employers-Please reply to Box $\mathrm{XIX}, 606$.

\section{Ad Closing for the August Issue is July 1}

\author{
To place your ad, call Mary E. \\ Kaufold at (412) 367-3036.
}

\section{POSTERMINARIES}

\section{Of Language and Languages}

An acquaintance of mine submitted a paper to a certain journal, regarded by many as the publishing paragon of the physics profession. The paper was accepted but there was one small difficulty. The editor took exception to the figure of speech which he had employed in order to create a simple picture of some otherwise obscure mathematics. He had referred to a "drunkard on a staircase."

At a time when most scientific articles are so soporific that train drivers and pilots should be forbidden even to look at them, why do editors object to language that has a bit of bite to it, or a personal flavour? Perhaps in this case it was considered to be a gratuitous insult to certain unfortunates? "Well," said my friend, "I tried a 'meandering aunt' and the answer from the Word Control Police was still 'no.'" I replied that I'd had a few of those wandering ladies in my own family, and found the analogy charming. No, he insisted, it was a "meandering ant."

Aunts may well be a sensitive social group to be respected at all times, but ants are surely not. Admittedly, if faced by a column of African army ants I would not choose to dispute the matter. How can a reference to a single lost member of the species be unacceptable?
So why then are sinister forces at work to maintain anodyne and anorexic English in our primary journals?

What possible justification could there be? I can think of only one, namely that English is the established lingua franca of science and as such it ought to operate on a restricted vocabulary and imagery, in the interests of accessibility.

The days are long past when Robert Boyle apologised at length for writing in his own language or when Maxwell learned Dutch in order to read the dissertation of van der Waals. We live in the age whimsically foreseen by the eccentric genius of electromagnetic theory, Oliver Heaviside, a century ago:

"Though sad, it is a fact that few Britons have any linguistic talent. It is not due to laziness but to a real mental incapacity. In fact one language is quite enough. Foreigners, on the other hand, seem to be gifted linguists, so much so that they have invented a large number of lingos and are commonly skilled in several at once. Very well, I would say let them give us poor islanders the benefit of their skills in doing all their best work into English, and why not make English the international scientific language? It would be all the same to the foreigners and a great boon to Great Britain and Irelanders, and the other English speaking peoples."

And so it came to pass. Does the price have to be the enforced boredom of a pallid, skeletal version of the language?

There are few signs of any resistance to this tendency. Most of us hardly expect anyone to look at our stuff anyway. The potential readers are too busy extending their own curricula vitae with papers that we shall not read either. Our appreciation of the current literature is approximately equivalent to that of a meandering ant in a library.

How depressing. Never mind-you can always write a piece, replete with rich irony and subtle allusion, for the MRS Bulletin.

DENIS L. WEAIRE Professor, Trinity College Dublin Editor, Journal of Physics: Condensed Matter

EDITOR's NoTE: Predictably, we found it impossible to keep our editorial pens strictly capped and must confess to consistently moving commas and periods inside quotation marks. We also added some quotation marks in the second paragraph, but we changed no words and retained the flavour of the original spelling.

Your words on matters of interest to materials scientists are welcome. Write to: Editor, MRS Bulletin, Materials Research Society, 9800 McKnight Road, Pittsburgh, PA 15237-6006. Phone (412) 367-3003; $\operatorname{fax}(412) 367-4373$. 